\title{
Indústria naval brasileira e a crise recente: o caso do Polo Naval e Offshore de Rio Grande (RS)
}

The Brazilian shipbuilding industry and the recent crisis: the case of Polo Naval and Offshore Rio Grande (state of Rio Grande do Sul)

Ana Paula F. D'Avila Maria Aparecida Bridi

\section{Resumo}

Este artigo analisa a reativação da indústria naval no Brasil na década de 2000 como resultado da política neodesenvolvimentista dos governos Lula e Dilma e que repercutiu imediatamente na criação de empregos e postos de trabalho no setor. A partir da contextualização histórica dessa indústria no Brasil, com os dados da Relação Anual de Informações Sociais (Rais), no Cadastro Geral de Empregados e Desempregados (Caged), do Sindicato Patronal (Sinval), bem como de entrevista com o sindicato dos trabalhadores (Stimmmerg) sobre emprego e sua dinâmica de contratação recente, constatamos que, embora essa atividade seja sazonal, caracterizada pela contratação por projetos (encomendas), a crise do emprego no período de 2015 encontra explicação no quadro político e jurídico que se instalou no Brasil.

Palavras-chave: neodesenvolvimentismo; políticas federais; indústria naval; emprego; crise.

\begin{abstract}
This article analyzes the reactivation of the shipbuilding industry in Brazil in the 2000s as a result of the neo-developmentalist policy of the governments of Lula and Dilma, which immediately reflected in the creation of jobs in the sector. Based on the historical contextualization of this industry in Brazil, with the use of data provided by the Annual Social Information List (Rais), by the General Roll of Employed and Unemployed Individuals (Caged), by the employers' association (SinavaL), and by an interview with the workers' union (Stimmmerg) on employment and its recent hiring dynamics, we have found that, although this activity is seasonal, characterized by the hiring of workers for specific projects, the employment crisis in 2015 can be explained by the political and legal scenario that has settled in Brazil.
\end{abstract}

Keywords: neo-developmentalism; federal policies; shipbuilding industry; employment; crisis. 


\section{Introdução}

0 crescimento econômico de um país nem sempre se reflete em desenvolvimento social, visto que o último se trata também de uma questão política. Nesse sentido, argumentamos que "a preocupação com a pobreza e a desigualdade de grandes estratos sociais é um tema relativamente novo no pensamento econômico e na elaboração política" (Mutis, 2013, p. 155). A desigualdade é, de fato, um problema social, mas tal questão "aparece e desaparece segundo os ciclos econômicos, atmosfera política e os paradigmas dominantes" (ibid.).

Segundo Ramalho e Verás de Oliveira (2013, p. 212), a partir da ascensão de Luís Inácio Lula da Silva (Lula) ao Governo Federal em 2003, houve a retomada da dimensão social por meio de um conjunto de políticas. Em virtude disso, o debate sobre desenvolvimento ressurgiu na agenda política e sociológica. Nessa direção, em termos de desenvolvimento socioeconômico, o Brasil vivenciou um período importante devido à estratégia adotada pelo governo federal, o que "não significa que ele não seja fruto de um esforço de teorização, de concepções ideológicas e de escolhas políticas" (Traspdini e Mandarino, 2013, p. 19).

0 crescimento econômico, ancorado na maior regulação do Estado e voltado para o consumo de massa, gerou, mediante a política de valorização do salário mínimo e de políticas sociais, uma melhor distribuição de renda (Pochmann, 2011, p.17), assim como políticas de criação de emprego. 0 Programa de Aceleração do Crescimento (PAC), Iançado em 2007, no segundo mandato de Lula, culminou com o fortalecimento do discurso neodesenvolvimentista, o qual, por sua vez, obteve respaldo numa conjuntura internacional, que proporcionou uma base para a retomada do crescimento econômico com distribuição de renda. Assim, segundo Verás de Oliveira (2014, p. 114), o governo acabou incorporando "o pressuposto desenvolvimentista do papel indutor do Estado, mas ao mesmo tempo o circunscreveu aos limites ditados pelos compromissos macroeconômicos".

No primeiro mandato de Lula, 0 aumento do preço das commodities, somado às políticas distributivas, resultou em crescimento econômico satisfatório (Bresser-Pereira e Theuer, 2012, pp. 825-826). Cumpre ressaltar que, em termos de debate, tanto o desenvolvimentismo quanto o neodesenvolvimentismo são frutos de "apreensões teóricas e propostas de política econômica, limitadas aos marcos do capitalismo em seus diferentes momentos históricos e padrões de reprodução ampliada do capital" (Traspdni e Mandarino, 2013, p. 3). Podemos dizer, assim, que o neodesenvolvimentismo ou novo desenvolvimentismo são conceitos utilizados "como referência à nova leva de estudos sobre desenvolvimento, posteriores à hegemonia neoliberal" (Boschi e Gaitán, 2013, p. 325).

Os estudos sobre o neodesenvolvimentismo ou novo desenvolvimentismo (e ainda sobre o social-desenvolvimentismo), em face do novo quadro político e econômico no período pós anos 1990, destacam que houve uma retomada de uma parte do pensamento estruturalista da Comissão Econômica para a América Latina e o Caribe (Cepal), ${ }^{1}$ mas essa revisão se deveu também ao "fracasso das políticas neoliberais que proclamaram o Estado mínimo e o poder autorregulador do mercado" da década anterior (ibid.). Para Boschi 
e Gaitán (ibid., pp. 325-326), o grupo liderado por Bresser-Pereira na Escola de Economia da Fundação Getúlio Vargas (FGV) tem em comum com a teoria cepalina a ideia do Estado como agente interventor responsável pela implementação de políticas (salário mínimo legal; transferências efetivas para os mais pobres; garantia de estabilidade de emprego; e combate à valorização cambial). Um segundo grupo situa-se na Universidade Federal do Rio de Janeiro (UFRJ) e na Associação Keynesiana Brasileira, os quais propõem ir além da questão macroeconômica, defendendo a compatibilidade entre crescimento e distribuição de renda. Dois organismos públicos também se debruçam sobre a questão:o Instituto de Pesquisa Econômica Aplicada (Ipea) é responsável por produzir e disseminar conhecimentos que dizem respeito à agenda do desenvolvimento, qual seja: a inserção externa, políticas de criação de emprego e proteção social, entre outras; e a Cepal, por sua vez, estimula a produção analítica e, em uma de suas vertentes, realiza a análise sobre os determinantes externos e internos e o papel ativo do Estado na economia política.

A "segunda geração" da Escola de Campinas constitui-se como fonte de análise crítica ao neodesenvolvimentismo. Esta enfatiza a "dimensão macroeconômica das políticas econômicas e outorga maior peso ao mercado privilegiando o estudo da relação entre desenvolvimento das forças produtivas e o mercado externo" (ibid., p. 327). Essa Escola propõe o social-desenvolvimentismo, pois entende o social como eixo central do desenvolvimento, o qual seria alcançado por meio do mercado interno e da ampliação do consumo da população excluída, situando a distribuição de renda como decorrência do desenvolvimento das forças produtivas. Combinando, portanto, a dimensão nacional e internacional (ibid., p. 328).

Assim, levando em consideração o debate teórico acima brevemente delineado, observamos que, a partir do governo Lula, o eixo social foi reinserido na agenda política por meio de uma série de políticas, dentre elas, a da valorização do salário mínimo, uma das formas de distribuir a riqueza gerada pelo país, e incentivo ao mercado interno via consumo. Em se tratando de política industrial, citamos o caso da reativação da indústria naval no Brasil e a descentralização dos estaleiros do Rio de Janeiro para outras regiões do País, tais como em Rio Grande, cidade situada ao sul do Rio Grande do Sul, e em Pernambuco, criando então novos territórios produtivos.

Interessa-nos, neste artigo, destacar um dos setores que se desenvolveu nesse período, o da indústria naval, que experimentou um boom em face do incremento das atividades petrolíferas e da descoberta do pré-sal pela Petrobras. Nessa conjuntura, surgiu a necessidade de construção de plataformas, navios e outras embarcações. 0 atendimento a tais demandas foi marcado pela adoção de uma política de forte conteúdo nacional, adotada pelo governo Lula. Assim sendo, a política estabelecida correspondeu à exigência de produção com percentual em torno de $60 \%$ de conteúdo nacional para o setor.

A retomada desse setor expressa o neodesenvolvimentismo (Bresser Pereira e Theuer, 2012) ou ainda o social-desenvolvimentismo (Boito Jr., 2012), que configurou o período Lula (2003-2010) e Dilma (2011-2014) em seu primeiro mandato, ao implementar políticas estratégicas para o setor naval. De acordo com Bresser-Pereira e Theuer (2012, p. 826), "o governo 
não chegou a ser novo-desenvolvimentista do ponto de vista macroeconômico, mas o foi na política industrial e na política social". Vejamos nas páginas que seguem a contextualização histórica desse setor, o seu incremento em uma região específica do Brasil, o Polo Naval e Offshore de Rio Grande (RS), seus reflexos no mercado de trabalho e o impacto da crise econômica e política vivenciada a partir de 2015, que se aprofunda em 2016.

\section{A indústria naval no Brasil: breve histórico sobre as políticas federais para o setor}

As políticas governamentais para o desenvolvimento da indústria naval no Brasil remetem à década de 1950, precisamente a partir do Plano de Metas (Pereira, 2013, p. 148). Já durante a ditadura militar, o governo lançou o Plano de Emergência da Indústria Naval (1969-1970), assim como os Planos da Construção Naval (PCN)1 (1970-1974) e 2 (1974-1980) (Pereira, 2013, p. 152). De acordo com Amaral, Gomide e Pires (2014, p. 191), foi com o Plano de Emergência de Construção Naval (1969-1970), assim como com o $1^{\circ}$ e $2^{\circ}$ PCN's que surgiram os primeiros estaleiros nacionais. Para Pereira (2013), os Planos subsidiaram os armadores através de financiamentos estatais e os protegeram da concorrência internacional. De 1980 a 1983, outro plano foi lançado, o Plano Permanente de Construção Naval, que objetivava conter a tendência à depressão econômica (Pereira, 2013. p. 152 apud Pasin, 2002).

Apesar dos planos do governo para implantação e manutenção da indústria naval no
País, a década de 1980 representou a decadência desse setor devido a inúmeros fatores, entre eles: a "crise da dívida externa, as reduções fiscais enfrentadas pelo governo federal"; aliado aos problemas de gestão no Fundo de Marinha Mercante (FMM) (Neto, 2014, p. 111) e à falta de financiamento público. Na década de 1990, esse cenário se agravou com a liberalização econômica e com a "desregulamentação do transporte marítimo de longo curso que expôs os armadores brasileiros à concorrência internacional" (Amaral, Gomide e Pires, 2014, p. 191). Como consequência, houve uma diminuição da frota nacional e, em contrapartida, o aumento dos afretamentos de embarcações estrangeiras, contraindo o setor da construção naval no Brasil (Motta, 2006 apud Amaral, Gomide e Pires, 2014).

Para Pasin (2002), o desenvolvimento da indústria naval brasileira adquiriu novo fôlego no final da década de 1990, com a promulgação da Lei do Petróleo e com o programa Navega Brasil. A Lei do Petróleo (lei 9.478/97) "abriu o mercado de exploração e refino do hidrocarboneto a novos players, além da Petrobras, acelerando a expansão da exploração de petróleo offshore" (p. 129).

De acordo com Dores, Lage e Processi (2012), em 1997 ocorreu a interrupção "do monopólio das atividades de exploração, desenvolvimento e produção de petróleo e gás natural" a partir de então, essas atividades "passaram a ser realizadas mediante contratos de concessão precedidos de licitação realizada pela Agência Nacional do Petróleo, Gás Natural e Biocombustíveis (ANP)" (p. 280). Além disso, foi regulamentado o transporte aquaviário pela lei 9.432/1997 que "disciplina os afretamentos de embarcações estrangeiras, define 
as navegações e cria o Registro Especial Brasileiro - REB" (Carvalhal, 2008, p. 4). Com isso, estabeleceu-se que poderiam ser registradas embarcações brasileiras, operadas por empresas brasileiras de navegação, e o financiamento se daria via o Fundo de Marinha Mercante (FMM) (Brasil, 1997a, lei 9.432/1997). Mas na primeira rodada de licitação em 1999,

[...] o processo considerava os índices de conteúdo local ofertados pelos concorrentes como um dos critérios de escolha do vencedor, de modo a estimular a aquisição de bens e serviços nacionais. A partir da sétima rodada, realizada em 2005, os índices de conteúdo local passaram a ser obrigatórios, sendo estipulados índices mínimos nas etapas de exploração, desenvolvimento e produção. É importante ressaltar que as embarcações utilizadas nas atividades petrolíferas são consideradas no cálculo do conteúdo local dos blocos. (Dores, Lage e Processi, 2012, p. 279; grifos nossos)

A lei 9.432/1997 já sinalizava a preferência, todavia, dado o índice de conteúdo local imposto pela primeira rodada de licitação em 1999 e a situação decadente dos estaleiros nacionais, as possibilidades da Petrobras eram limitadas. Somente em 2005, com as políticas federais voltadas para o setor e com a obrigatoriedade de uma porcentagem de conteúdo local, é que a indústria naval brasileira começou a ser efetivamente reativada.

Em 1999, o Programa de Renovação da Frota de Apoio Marítimo I (Prorefam I), lançado pela Petrobras, "oferecia contratos de afretamento de oito anos para 22 embarcações a serem construídas no país" (ibid.). Nessa primeira etapa do programa, "foram licitadas 22 embarcações, mas três contratos foram cancelados" (ibid., pp. 279-280). A segunda etapa do programa foi iniciada em 2003 e contratou mais trinta novas embarcações e 21 modernizações. Em 2008,

já no âmbito da Política de Desenvolvimento Produtivo (PDP), a Petrobras lançou a terceira etapa do Prorefam, que previa a contratação de 146 novas embarcações de apoio no período de 2008 a 2016 para atuar, inclusive, em campos do pré-sal. Nessa etapa, o programa contou com a exigência de conteúdo local mínimo. (Ibid.)

O Prorefam estimulou a retomada de investimentos e a demanda do setor. Todavia, conforme dito acima, a efetiva reativação da indústria naval nacional, setor em decadência desde a década de 1980, deu-se a partir da terceira etapa do Prorefam. Em 2003, o Ministério de Minas e Energia (MME) juntamente com a Petrobras lançou o Programa de Modernização da Indústria Nacional de Petróleo e Gás (Prominp), o qual estabeleceu em lei o conteúdo local. ${ }^{2}$ Em 2004, a Transpetro, que é a subsidiária de logística da Petrobras e responsável junto com esta por organizar as demandas da indústria naval, pautando o desenvolvimento do setor, lançou o Programa de Modernização e Expansão da Frota - Promef I, de 2004, e Promef II, de 2008 (Amaral, Gomide e Pires, 2014, p. 194). A partir de então, grupos industriais nacionais passaram a investir na construção de estaleiros.

Cumpre ressaltar alguns fatores que foram decisivos nessa escolha, tais como: a pressão de setores da indústria naval representados pelo Sindicato Nacional de Indústria da Construção e Reparação Naval e Offshore (Sinaval), bem como os "altos custos com o afretamento 
por parte da Petrobras, a necessidade de renovação da frota da Transpetro, a descoberta de campos em águas profundas", o que demandou mais embarcações, "e mudanças na política de conteúdo local nas rodadas de licitação da Agência Nacional de Petróleo (ANP)" (Carvalho, 2011 apud D'Avila e Bridi, 2015). Desse modo, a atuação do governo federal reuniu esforços junto à Petrobras e à Marinha Mercante, que operacionalizaram a política voltada para a reativação da indústria naval, via investimentos em infraestrutura e modernização dos antigos estaleiros situados no Rio de Janeiro, bem como a instalação de novos estaleiros ${ }^{3} \mathrm{em}$ diversas regiões do País.

0 ano de 2006 marca o início da instalação do Polo Naval e Offshore na cidade de Rio Grande (RS), tendo como marco a construção do dique seco, uma infraestrutura crucial para a construção e reparação de embarcações, assim como equipamentos marítimos vindouros. ${ }^{4}$ O Polo Naval e Offshore, inaugurado em 2010, foi estruturado em torno de três estaleiros: Estaleiro Rio Grande 1 e 2 (ERG 1, ERG 2) e Honório Bicalho. Entre 2013 e 2014, registrou o pico de atividades, período no qual foram entregues as Plataformas: P-63; P-55; P-58 e o casco da P-66, resultando, portanto, em movimento de contratação, bem como em desmobilização de mão de obra (ibid.).

Para o Polo Naval e Offshore, a "Petrobras possui direito de uso através de comodato, por dez anos contados a partir de setembro de 2010 e possibilidade de renovar contrato de uso por mais dois anos" (Fabres, 2014, p. 33). A Petrobras assinou contratos de concessão, via licitação, com um consórcio empresarial e com uma empresa, o primeiro está voltado para a instalação e integração de módulos nas plataformas de petróleo. E a empresa, por sua vez, tem na sua carteira a construção de oito cascos replicantes do tipo FPSOs (Floating Production, Storageand Off-Loading Plataffor ou Plataforma Flutuante de Produção, Armazenamento e Escoamento) - replicantes que são plataformas feitas como réplicas, idênticas entre si, na qual cada uma repete o projeto da anterior, permitindo ganhos de custos e de prazos na construção - e três navios sondas para exploração do pré-sal (D'Avila e Bridi, 2015). Isso refletiu socialmente, na medida em que alterou positivamente a dinâmica do mercado do trabalho, como podemos acompanhar nos dados a seguir.

\section{Empregos gerados pela construção naval brasileira: um breve histórico}

Entre 1956 a 1961, vigorou o Plano de Metas, articulado pelo Governo Gederal, e em 1958 o Fundo da Marinha Mercante fora criado, ambos foram importantes para o setor naval do Brasil, que começava a ser estimulado. Com o desenvolvimento dessa indústria, observa-se a criação de um mercado de trabalho, como podemos acompanhar na série histórica da Figura 1. 0 volume de empregos na construção naval como um todo correlaciona-se com as políticas adotadas pelos governos federais.

Em 1960 a indústria naval possuía um total de 1.430 empregos. Em 1966 a primeira plataforma fixa (P-1) foi construída no Estaleiro Mauá, no Rio de Janeiro. Durante a ditadura militar, em 197018 mil empregos foram gerados, pois, em 1969, o governo lançou o Plano Emergência da Indústria Naval (19691970), assim como os Planos da Construção 
Figura 1 - Empregos na construção naval brasileira: entre 1960 e 2011

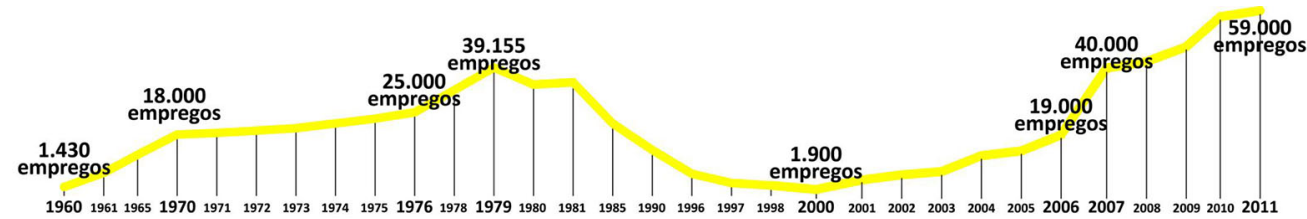

Fonte: Sinaval $(2012$, p. 8).

Naval 1 e 2 citados anteriormente (Sinaval, 2012, p. 8). Nesse contexto, o Brasil conquistou $02^{\circ}$ lugar mundial em volume de encomendas de construção naval (ibid.). Como é possível observar na Figura 1, em 1976 havia 25 mil empregos, e no seu ápice, em 1979, a indústria naval gerava 39.155 empregos. Todavia, com a recessão econômica dos anos 1980, esses empregos foram dimuindo e, na década de 1990, esse fenômeno foi asseverado pela desregulamentação do transporte marítimo de longo curso, que inviabilizou a operação dos armadores brasileiros (ibid.). 0 desmonte foi tamanho que, no ano de 2000, a indústria naval apresentava apenas 1.900 empregos. Somente a partir de 2005, o nível de emprego do setor se elevou significativamente, como analisamos a seguir.

\section{A retomada da indústria naval e a evolução do emprego}

A reativação da indústria naval a partir de 2003 se deu via iniciativa do Governo Federal com o prosseguimento de rodadas do
Prorefam e a criação de outros programas, tais como: o Prominp e o Promef, em conjunto com a Petrobras e com a Marinha Mercante, voltando o foco para conteúdo nacional. A partir de 2005, a indústria naval começou a gerar um significativo número de empregos devido à demanda crescente de encomendas aos (antigos e novos) estaleiros brasileiros, como demonstra a Tabela 1 que sintetiza a evolução no número de empregos.

Em 2005, havia 14.442 empregos, conforme os dados, houve um salto para 82.472 em 2014. De acordo com a estatística levantada pelo Sinaval, a partir de 2014 começa uma queda no emprego, isto é, de 82.472 caiu para 43.745 em 2016 (dados de janeiro a junho). Por um lado, o Sinaval, ao analisar essa variação e queda, explica que ela também se deveu à conclusão de várias obras, com as entregas de navios e plataformas que geraram a desmobilização da mão de obra. Por outro lado, o sindicato patronal também avaliou que o decréscimo, já observado em 2015, é um indício da "crise da economia brasileira e da Petrobras a partir do segundo semestre de 2014, devido à Operação Lava Jato" ${ }^{5}$ (Sinaval, 2014, p. 2). 
Tabela 1 - Evolução do emprego nos estaleiros brasileiros de 2005 a 2016*

\begin{tabular}{c|c}
\hline Ano & Empregos gerados \\
\hline 2005 & 14.442 \\
2006 & 19.600 \\
2007 & 29.124 \\
2008 & 33.277 \\
2009 & 40.500 \\
2010 & 56.112 \\
2011 & 59.167 \\
2012 & 62.036 \\
2013 & 78.136 \\
2014 & 82.472 \\
2015 & 57.048 \\
$2016^{*}$ & 43.745 \\
\hline
\end{tabular}

Fonte: Sinaval (2014 e 2016).

*Os dados de 2016 são de janeiro a junho.

Tabela 2 - Empregos nos estaleiros por região de janeiro a junho de 2016

\begin{tabular}{l|r|r|r|r|r|r}
\hline \multicolumn{1}{c|}{ Regiões } & Janeiro & Fevereiro & \multicolumn{1}{c|}{ Março } & \multicolumn{1}{c|}{ Abril } & \multicolumn{1}{c}{ Maio } & Junho \\
\hline Sudeste & 24.296 & 22.628 & 22.272 & 21.236 & 19.534 & 16.810 \\
Nordeste & 5.610 & 5.600 & 7.553 & 7.340 & 6.654 & 5.868 \\
Norte & 8.300 & 8.379 & 8.377 & 9.528 & 9.597 & 7.953 \\
Sul & 12.870 & 12.672 & 12.761 & 12.824 & 12.762 & 13.114 \\
Total & 51.076 & 49.279 & 50.963 & 50.928 & 48.547 & 43.745 \\
\hline
\end{tabular}

Fonte: Sinaval (2016).

No ano de 2015, a redução dos empregos persistiu e, em 2016, ela piora, pois, se comparada ao ápice do ano de 2014, a indústria naval perdeu 38.727 postos de trabalho. Observamos na Tabela 2 os números disponibilizados pelo Sinaval, por região do País.

De acordo com o Sinaval (2016, p. 2), comparativamente a região Sudeste continua sendo a maior empregadora, responsável por 16.810 contratações, mas também apresenta uma perda significativa, com a redução de 7.486 vagas. Na região Sul, considerada a segunda maior empregadora, houve 0 aumento de 244 vagas desde janeiro. Por sua vez, a região Nordeste aumentou 258 empregos, mas reduziu suas vagas se comparadas ao mês de maio. Por fim, a região Norte perdeu 347 vagas desde janeiro. Os dados sinalizam, portanto, que em 2016 a tendência mais geral foi de queda do emprego no segmento. 
No Estaleiro Rio Grande (ERG - Rio Grande/RS), a situação destoa um pouco desse cenário porque o Banco Brasil Plural "assumiu a gestão da conta vinculada ${ }^{6}$ relativa ao contrato com a Petrobras para a construção dos cascos dos FPSOs replicantes" (Sinaval, 2015, p. 2). No segundo semestre de 2013, a Petrobras e o consórcio empresarial "assinaram um contrato para a fabricação das plataformas ao custo de US\$1,3 bilhão. Logo em seguida, tendo em vista o surgimento das denúncias investigadas pela Operação Lava Jato" (G1, 2016a), a Petrobras e o consórcio empresarial não entraram em acordo sobre os aditivos do contrato. Somente após intensa mobilização do Sindicato dos Trabalhadores das Indústrias Metalúrgicas e de Material Elétrico de Rio Grande e São José do Norte (Stimmmerg) em 2015, realizou-se uma reunião entre a Petrobras e o consórcio empresarial em que estavam presentes também o presidente do sindicato dos trabalhadores, trabalhadores e o prefeito do município de Rio Grande. Nessa reunião, foi firmado um acordo sobre os aditivos do contrato da P-75 e da P-77, ficando estabelecido que ambas as plataformas seriam construídas na cidade, ao invés de enviadas para produção na China (como já aconteceu com o casco da P-68). Assim, o Estaleiro retomou timidamente suas atividades, mas o número de postos de trabalho estimado é de, no máximo, dois mil, de acordo com o sindicato dos trabalhadores.

Além das informações disponibilizadas pelo sindicato patronal, buscamos outras fontes de dados para demonstrar como as dinâmicas políticas e econômicas nacionais refletem no âmbito local e regional.

Nesse sentido, apresentamos a Tabela 3, obtida através da Relação Anual de Informações (Rais/MTE) para o grupo de construção de embarcações em Rio Grande/RS, de acordo com o vínculo ativo de 2010 - ano em que o Polo Naval e Offshore foi inaugurado - até 2015 para o grupo construção de embarcações, de acordo com a CNAE (Classificação Nacional de Atividades Econômicas), em Rio Grande/RS.

Como podemos observar, houve um movimento crescente de vínculos ativos para o grupo de construções de embarcações, chegando, em 2014, com 7.479 vínculos. Todavia, em 2015 esse número decresceu para 5.993, seguindo a tendência do setor em geral.

A indústria naval contribuiu para o crescimento econômico de Rio Grande. Conforme

Tabela 3 - Vínculo ativo (empregos) de 2010 a 2015: grupo construção de embarcações Rio Grande/RS

\begin{tabular}{c|c}
\hline Ano & Total \\
\hline 2010 & 571 \\
2011 & 2.310 \\
2012 & 6.494 \\
2013 & 7.226 \\
2014 & 7.479 \\
2015 & 5.993 \\
\hline
\end{tabular}

Fonte: Rais/MTE. 
Klein (2016), o prefeito da cidade explicou que, em 2009, o orçamento era de $\mathrm{R} \$ 260$ milhões e que, no contexto atual, foi triplicado para cerca de R\$630 milhões. Além disso, "a instalação da indústria naval atraiu investimentos em outras áreas. Entre os empreendimentos, o prefeito citou as duplicações das rodovias BR-116 e BR392, além de aumento no número de cursos da Universidade Federal do Rio Grande (Furg)" (ibid.). A Petrobras, por sua vez, é a grande cliente do Polo Naval, desta forma o futuro da indústria naval depende do planejamento dos investimentos da estatal (ibid.).

Com a elevação do número de empregos, a cidade de Rio Grande vivenciou mudanças importantes, uma vez que se tornou um polo de atração de mão de obra, o que provocou também alterações nas condições de vida, de mobilidade e de moradia na região. Da mesma forma que os empregos gerados contribuíram para um certo bem-estar na medida em que as pessoas conseguiam produzir sua subsistência, por sua vez, o desemprego e a redução de postos de trabalho causaram insegurança e crise social. É nesse cenário que podemos constatar o impacto da dinâmica econômica e das decisões políticas na cidade.

\section{A crise e seus reflexos imediatos no trabalho: incerteza e desemprego}

\author{
A história do sistema capitalista, conforme \\ Bridi (2006, p. 285), "aponta para certa cro- \\ nicidade nas crises, que, por sua vez, pode \\ desembocar em transformações estruturais
}

ou não da sociedade". Ao analisar as crises que assolam o capitalismo e seus reflexos para os trabalhadores, a autora afirma que a noção de crise é inconcebível sem a compreensão de sociedade como um sistema capaz de sofrer crises, pois a própria mudança implica um caráter crísico (Bridi, 2005). As crises conjunturais e/ou estruturais são inerentes ao sistema capitalista, com base em estudos de Morin (1998) e de Habermas (1980) sobre o fenômeno das crises. A autora propõe um pensamento que seja capaz de refletir e analisar as crises como "situação de transição e de transformação inscrita no âmbito da desregulação e desorganização do fenômeno social, a ser explicada por um conjunto de redes complexas e inter-relacionadas entre si" (Bridi, 2005, p. 50).

A fim de evitar o uso do conceito de crise de modo banalizado, que redundaria em conteúdo pouco explicativo, orientamo-nos em analisar a crise partindo dos pressupostos de que estas

a) se encontram inscritas num determinado tempo e numa espiralidade dialética; b) supõem situações de conflitos, incertezas, rupturas de um determinado equilíbrio, bloqueios; c) são momentos de incerteza e mudança, mas também de decisão e de transição; d) são decorrências das transformações estruturais e, particularmente, dos processos de desregulamentação do trabalho e das contradições inerentes ao sistema capitalista; e) afetam a sociedade por essa conter antagonismos, contradições e conflitos; e finalmente, as mudanças crísicas são aquelas que colocam em risco a identidade de um sujeito social, de uma instituição. (Bridi, 2006, p. 284) 
A autora invoca, assim, um conceito de crise como momento de indeterminação, de incerteza, mas também de transição. Essa transição pode levar a patamares progressivos, quando as mudanças produzem avanços sociais, políticos e econômicos e/ou regressivos quando a tendência se inverte (Morin 1998 e Bridi, 2005). No caso em tela, a crise possui várias facetas e protagonistas, mas os fatores econômicos, jurídicos e políticos desempenham papeis-chave no quadro de inversão e de retrocesso em termos trabalhistas vigentes.

Engendrado nessa atmosfera, temos a Operação Lava Jato que foi deflagrada em março de 2014, tornando público um esquema de propinas ou contratos superfaturados a partidos políticos, pessoas físicas e jurídicas. Essa operação se insere no contexto mais amplo que redundou em um movimento de crescimento do desemprego no Brasil e que também impactou fortemente as contratações nos estaleiros brasileiros. A crise econômica e política experimentada pelo Brasil desde então, segundo Krein (2016), vem sendo utilizada, inclusive, "pelas entidades patronais, apoiada em analistas pró-mercado, para colocar na agenda uma reforma trabalhista", que desconstrói os direitos conquistados historicamente e, além disso, suprime as conquistas no âmbito do trabalho no Brasil. Nesse sentido, a crise teria um caráter fortemente regressivo.

A crise que redundou em demissões, no segmento de construção de embarcações, a princípio, de teor conjuntural, produziu efeitos imediatos e regressivos no que tange à dinâmica do emprego, como podemos acompanhar na Tabela 4, conforme os dados do Cadastro Geral de Empregados e Desempregados (Caged/MTE). ${ }^{7}$

No ano de 2015, foram admitidos, portanto, 1.052 trabalhadores e desligados 2.782, refletindo um saldo negativo de 1.730. Assim, com base na noção de crise, argumentamos que, a partir de 2015, o cenário econômico no Brasil agrava-se, refletindo, por exemplo, o aumento do saldo negativo de postos de trabalho do Polo Naval e Offshore de Rio Grande.

A Tabela 5 demonstra o movimento das admissões e demissões para a cidade de Rio Grande/RS, de acordo com a Cnae 2.0, para o grupo construção de embarcações de janeiro a outubro de 2016.

Tabela 4 - Admitidos e desligados em 2015: grupo construção de embarcações, município de Rio Grande/RS

\begin{tabular}{l|r|r|r|r|r|r|r|r|r|r|r|r|r}
\hline & Jan & Fev & Mar & Abr & Maio & Jun & Jul & Ago & Set & Out & Nov & Dez & Totais \\
\hline Admitidos & 2 & 39 & 427 & 214 & 139 & 71 & 7 & 80 & 14 & 23 & 24 & 21 & 1.052 \\
Desligados & 134 & 453 & 45 & 83 & 211 & 238 & 72 & 503 & 332 & 59 & 41 & 611 & 2.782 \\
Saldo & - & - & - & - & - & - & - & - & - & - & - & - & -1.730 \\
\hline
\end{tabular}

Fonte: Caged/MTE. Tabela adaptada pelas autoras. 
Tabela 5 - Admitidos e desligados de janeiro a outubro de 2016: município de Rio Grande/RS

\begin{tabular}{l|c|c|c|c|c|c|c|c|c|c|c}
\hline & Jan & Fev & Mar & Abr & Maio & Jun & Jul & Ago & Set & Out & Totais \\
\hline Admitidos & 40 & 98 & 77 & 204 & 163 & 164 & 14 & 3 & 28 & 28 & 819 \\
Desligados & 194 & 109 & 25 & 166 & 89 & 32 & 124 & 224 & 281 & 500 & -1.744 \\
Saldo & - & - & - & - & - & - & - & - & - & - & -925 \\
\hline
\end{tabular}

Fonte: Caged/MTE. Tabela adaptada pelas autoras.

Em 2016, pelo menos até outubro, observamos que os admitidos foram 819; em contrapartida, o número de desligamentos é elevado e corresponde a 1.744, apresentando um saldo negativo de 925 postos de trabalho. Comparados ao ano de 2015, embora ainda faltem dois meses para finalizar esse balanço prévio, os dados do Caged/MTE apontam que, por enquanto, em 2016, perdeu-se menos postos de trabaIho (925). Esse fato está, de alguma maneira, correlacionado a um conjunto de ações, quais sejam: uma empresa deverá entregar os cascos encomendados para a Petrobras até 2018, mas, como passa por uma crise, o Banco Brasil Plural "assumiu a gestão da conta vinculada relativa ao contrato com a Petrobras para a construção dos cascos dos FPSOs replicantes" (Sinaval, 2015 , p. 2). Assim, mesmo que reduzindo o número de empregos, as atividades continuaram tendo em vista a prioridade em manter a produção das duas plataformas acordadas e 0 cumprimento do prazo para entrega.

Em relação ao consórcio empresarial, o sistema é diferente porque a cada plataforma o contrato é revisto. Desse modo, com a crise se torna cada vez mais difícil a negociação de possíveis aditivos dos contratos, resultando, portanto, numa falta de perspectiva em relação a obras futuras da P-75 e P-77. Se o movimento de demissões que ocorreu em 2015, teve forte ligação com a situação de envolvimento das empresas em problemas jurídicos, é preciso mencionar também a "natureza sazonal" dessa atividade, conforme analisaram D'Avila e Bridi (2015). Para as autoras, a produção por encomendas apresenta muita similaridade com a produção por projetos, o que corrobora com esse quadro de crise que se soma ao mercado de trabalho fluido e flexível.

Além dos problemas ocasionados pelo desemprego, recorrente ao término dos projetos, essa sazonalidade, segundo o dirigente do sindicato dos trabalhadores de Rio Grande, traz dificuldades para a atividade sindical:

0 sindicato hoje ele não tem um meio de controlar esse trabalhador hoje. Por quê? Porque hoje tu vai lá na empresa, amanhã tu é sócio, tu saiu e tu está na outra [empresa], então pro meu sistema ele é sócio da empresa $A$ e quando ele saiu da empresa $A$ e foi para a $B$, ele perdeu 0 vínculo. $E$ eu não tenho como saber se ele não vem aqui. Alguns vêm, [pois] a gente 
tem muitos sócios fieis que vem aqui e [diz] "olha eu saí da empresa". Então como eu te digo essa questão sazonal aí é muito grande e a gente não tem esse controle. Então é muito difícil controlar aonde que está o nosso trabalhador hoje! Eu sei que se eu for para a porta da fábrica eu vou ver ele ali. Pô o cara trocou de jaqueta [...]. (Dirigente sindical, Rio Grande, $1^{\circ}$ de julho de 2016$)^{8}$

A mudança de empresa por parte do trabalhador dificulta até o controle do sindicato em relação aos seus sócios. A ação coletiva organizada, conforme Bridi (2006, p. 295), tem relação com a "capacidade de as instituições desenvolverem uma identidade que envolve a experiência e a consciência de pertencimento a um coletivo e de um compartilhamento de referencial comum, enquanto fonte de significado e experiência de um grupo, de povo". Para a autora, essa é uma das razões da crise no sindicalismo atual produzidas pelas novas configurações do trabalho e das formas de contratação flexíveis. Um dos grandes impulsionadores da ação coletiva é a possibilidade de aglutinação dos trabalhadores "em torno de interesses comuns". Essa dificuldade, do processo de identificação dos trabalhadores, dadas as transformações no mercado de trabaIho, se não obstaculiza totalmente, dificulta a ação (ibid.).

0 desemprego em momentos de crise, no entanto, é um dos maiores entraves para a ação coletiva, pois coloca os trabalhadores na defensiva. A falta de trabalho, além de comprometer a vida e a subsistência do trabalhador, potencializa a crise social. A centralidade do trabalho encontra-se expressa na fala do dirigente sindical que afirma:
Eu acho, assim, que a grande coisa seja qual for o governo, nós temos que defender 0 trabalhador primeiro, a bandeira: trabalho. [...] Estou sendo bem sincero, quer malhar o sindicato? Malha, mas dá emprego para o trabalhador. Quer torrar o sindicato? Torra. Mas dá emprego para 0 trabalhador, é a minha opinião [...]. (Dirigente sindical, Rio Grande, $1^{\circ}$ de juIho de 2016)

Quando indagamos sobre o desemprego, o dirigente sindical responsabilizou às opções feitas pelos empresários em momentos de crise.

[...] a visão que eu tenho do desemprego hoje ele está dentro da parte do empresário que não quer perder dinheiro. Então o que que ele faz? Eu vou demitir cinco, mas eu vou ficar com o dinheiro aqui quando melhorar eu contrato de novo. Ele não perde dinheiro, mas nós sim. (Dirigente sindical, Rio Grande, $1^{\circ}$ de julho de 2016)

0 sindicalista, portanto, atribui o desemprego no Polo naval a uma questão de escolha empresarial, no qual estes preferem economizar na contratação, mediante a desmobilização da mão de obra. A explicação para esta desmobilização tem relação com a sazonalidade bastante característica de alguns segmentos do Polo Naval. Quando olhamos para os dados de 2015 e 2016, considerando o cenário nacional e internacional, contudo, podemos observar que a crise que se abateu sobre o setor naval no Brasil, não ocorreu apenas em Rio Grande, mas também implicou em enormes contingentes de demissões em outros polos navais como do Nordeste e norte do país. 
Nesse sentido, ao indagarmos sobre as razões para esta crise de emprego, que se abateu sobre o setor Naval, é preciso analisar também as raízes mais profundas que se encerram nos problemas econômicos vivenciados pela economia capitalista global. Ou seja, diversos fatores conjugaram-se e remeteram à crise no setor naval e à crise do emprego neste e também em outros setores da economia. No plano internacional, a crise que levou à retração da economia chinesa e a redução dos preços das commodities, a redução do preço do petróleo bruto, por exemplo, segundo Lacerda (2016), afetou tanto as exportações quanto, de forma contundente, inibiu novos projetos e novos investimentos devido à queda da sua receita e rentabilidade. Ademais, há um vínculo entre crise no setor naval e as decisões judiciais no plano da lava-jato, visto que estas se dão sobre um conjunto de empresas ligadas à Petrobras, causando a desorganização da cadeia de óleo e gás, ${ }^{9}$ pois se trata de um segmento cujo forte crescimento no período recente se deu vinculado a mesma.

\section{Considerações finais}

A crise econômica e política brasileira afetou de modo particular a cidade de Rio Grande. A instalação do Polo Naval e Offshore representava uma oportunidade de emprego para milhares de trabalhadores oriundos não só do estado do Rio Grande do Sul, mas do país. Esse empreendimento novo, a princípio de longo prazo, alavancou também uma cadeia de investimentos no ramo imobiliário, em mobilidade urbana, etc. Em estudos realizados pela comunidade acadêmica a fim de, apresentar os principais gargalos da cidade, demonstrou-se que tal empreendimento implicou em investimento no comércio em geral, no setor de serviços, e uma gama de atividades que dinamizaram a economia da cidade e região. Também em relação a demografia, a população de Rio Grande, por exemplo, saltou de 197.228 habitantes em 2010, para 207.036 habitantes em 2014, conforme dado do IBGE (Instituto Brasileiro de Geografia e Estatística, 2015 apud D’Avila e Bridi, 2015).

A Operação Lava Jato impactou fortemente a retomada do setor naval, visto que as empresas envolvidas interromperam sua inserção em novos projetos, por estarem impedidas, ao menos momentaneamente, de participarem de licitações e devido ao atraso no pronto estabelecimento de acordos de leniência. ${ }^{10}$ Entretanto, não temos por objetivo dimensionar o grau de responsabilidade pela crise de cada um dos atores, mas sim apontar um contexto imbricado entre o nacional e o global. No Brasil, conforme demonstrado, o setor vem encolhendo, as obras estão paralisadas e os estaleiros vêm sendo fechados. Pode-se dizer que o Polo Naval em Rio Grande é, do ponto de vista econômico, o grande empreendimento industrial responsável por dinamizar a cidade. Portanto, a falta de perspectiva de uma reinserção nessa indústria significa para o trabalhador - na melhor das hipóteses - ter que se voltar para outros ramos, com contrapartidas salariais menores, tais como o comércio e a agricultura, por exemplo.

A adoção da gestão da conta vinculada ao contrato das plataformas com a Petrobras, pelo Banco Brasil Plural, é um dos fatores pelos quais o Polo Naval continua em funcionamento, pois a partir disso foi possível realizar 
o pagamento aos fornecedores e aos trabaIhadores e trabalhadoras. No outro estaleiro, aguarda-se a chegada de uma plataforma. 0 clima de instabilidade é a regra, e cresce a cada fase da Operação da Lava Jato anunciada na mídia, sendo, em certa medida, utilizada como justificativa pelas escolhas empresariais em empurrar as encomendas de plataformas para a Ásia, ainda que as razões principais estejam no afrouxamento da política de "conteúdo nacional" e a busca da redução do custo da mão de obra. Desse modo, no caso de Rio Grande, uma das principais preocupações "é com a construção das plataformas P-75 e P-77, cujo contrato foi assinado em 2013 e prometia a contratação de 2 mil trabaIhadores. Por enquanto, as obras não começaram" (G1, 2016b).

É possível afirmar que a preocupação com a desigualdade e, consequentemente, a formulação de políticas sociais, no caso estudado a importância crucial do Estado no que tange às políticas de incentivo à indústria naval nacional, estiveram presentes nos governos Lula e Dilma. Em termos de projeto neodesenvolvimentista pairam enormes incertezas. Um dos aspectos desafiadores diz respeito à nova divisão internacional do trabalho, principalmente pelo fato de que as plataformas vêm deixando de ser fabricadas no Brasil e passando a ser fabricadas pela China.

No que diz respeito à atuação dos governos Lula e Dilma (no primeiro mandato), que são considerados neodesenvolvimentistas, há vários aspectos problemáticos, entre eles o processo de impeachment da presidenta eleita democraticamente. 0 presidente ainda quando interino sinalizou propostas de privatização e a diminuição do papel do Estado, mediante o redimensionamento de políticas sociais, por exemplo. Além disso, o ajuste fiscal e a inflação configuram um cenário socioeconômico e político tenso, que onera cada vez mais a população.

Setores conservadores atribuem as dificuldades econômicas do País às políticas de cunho social e ao consumo desenfreado e defendem claramente o retraimento do Estado e maior atuação do mercado, conformando uma atmosfera muito semelhante àquela da década de 1990. Essa perspectiva neoliberal foi consubstanciada na controversa proposta de ajuste fiscal denominada PEC 241, transformada, no Senado, em PEC 55 pelo governo de Michel Temer, após assumir a presidência da República a partir do impedimento de Dilma Rousseff em 2016. Tratando-se de uma medida que altera a Constituição Federal e, por conseguinte, os mecanismos que viabilizam a atuação do Estado para gerir o modelo de desenvolvimento econômico e social do País, ao prever o congelamento dos investimentos do Estado por vinte anos.

Além disso, há o risco de reprimarização da pauta de exportação e desindustrialização, assim como a questão da garantia de ampliação de investimentos entre sistema de proteção social e o regime produtivo (Boschi e Gaitán, 2013, p. 329). Para os autores, o desafio está num projeto de desenvolvimento de longo prazo "com patamares definidos em termos de políticas de inovação, industrial e social". Contudo, devido à conjuntura atual de crise política e econômica do País, o próprio neodesenvolvimentismo está em crise. Para Krein (2016), estamos vivenciando o esgotamento do crescimento econômico experimentado entre 2004 e 2013, somado ao "avanço das posições 
conservadoras na sociedade que foram ganhando força para implementar a sua agenda conservadora". 0 autor argumenta que há uma reversão, principalmente com o aumento do desemprego e o corte dos gastos públicos.

A crise, portanto, como analisa Bridi (2006), traduz-se como um movimento de incerteza, mas também de transição. Assim, de 2003 até meados de 2014, o País vivenciou um movimento progressivo, em geral, de avanços sociais, políticos e econômicos. Todavia, a partir do segundo semestre de 2014, a tendência começa a se inverter e expressa, em 2016, uma regressão, uma vez que a democracia sofre um revés e se evidencia um aparente desequilíbrio entre os poderes da República. A regressão tende a se consubstanciar também nos ataques aos direitos dos trabalhadores, a partir de medidas que alteram o trabalho. Embora a reforma trabalhista, proposta pelo governo, tenha sido transferida para 2017, o Supremo Tribunal Federal, no período após a consumação do impedimento de Dilma Rousseff, tomou decisões interpretadas por considerável parcela das centrais sindicais como medidas contra os trabalhadores, entre elas: a anulação da desaposentação e da súmula 277 - que assegurava a renovação automática de cláusulas sociais sem novo acordo como, também, a autorização dada pelo Supremo de corte do ponto do funcionalismo público em greve. Trata-se de reformas com grandes impactos para os trabaIhadores, trazendo como uma das consequências a fragilização da ação coletiva (ibid.).

O futuro da indústria naval, por sua vez, está atrelado aos rumos políticos do País, visto que sua manutenção e desenvolvimento estão estritamente ligados às políticas federais. 0 resultado prático dessa multiplicidade de fatores econômicos, políticos e jurídicos, conforme apresentamos neste artigo, traduziu-se de forma quase imediata na cidade de Rio Grande, por exemplo, em crescimento do desemprego. Ponderamos, contudo, que a compreensão dos efeitos e consequências da crise política e econômica brasileira e seus rebatimentos na dinâmica econômica e social na região focada no artigo, em toda sua complexidade, requerem (re)visão histórica e análise de como os atores agem e reagem ante as mudanças em curso.

\section{Ana Paula F. D'Avila}

Universidade Federal do Paraná, Setor de Ciências Humanas, Departamento de Ciência Política e Sociologia, Grupo de Estudos Trabalho e Sociedade. Curitiba/PR, Brasil.

davilaanap@outlook.com

\section{Maria Aparecida Bridi}

Universidade Federal do Paraná, Setor de Ciências Humanas, Departamento de Sociologia, Programa de Pós-Graduação em Sociologia. Curitiba/PR, Brasil.

macbridi@gmail.com 


\section{Notas}

(1) A Comissão Econômica para a América Latina e o Caribe (Cepal) foi criada no final da década de 1950, no âmbito da Organização das Nações Unidas (ONU), para compreender o contexto latinoamericano. A Cepal tinha como pressuposto básico analisar as relações entre centro-periferia e as mudanças em estruturas sociais, tendo como principais pensadores os economistas Raúl Prebisch e Celso Furtado.

(2) Fonte: http://www.prominp.com.br/prominp/pt_br/conteudo/sobre-o-prominp.htm Acesso em: 26 de nov. 2016.

(3) Estaleiro Bobi em Amazonas, Estaleiro Rio Maguari no Pará, Estaleiro Inace no Ceará, Estaleiros Atlântico Sul e Vard Promar em Pernambuco, Estaleiro Eisa em Alagoas, Enseada Industrial Naval S.A. na Bahia, Estaleiro Jurong Aracruz no Espírito Santo, vinte estaleiros situados no Rio de Janeiro, seis estaleiros situados em São Paulo, quatro estaleiros em Santa Catarina e quatro estaleiros no Rio Grande do Sul. Fonte: http://sinaval.org.br/wp-content/uploads/Mapa_Brasil_ Dez14.pdf. Acesso em: 10 maio 2016.

(4) Disponível em: http://memoria.ebc.com.br/agenciabrasil/noticia/2006-01-26/petrobrasinaugura-canteiro-de-obras-da-plataforma-p-53-no-litoral-gaucho. Acesso em: 19 set 2014.

(5) Deflagrada, em março de 2014, a Operação Lava Jato é uma investigação da Polícia Federal que apura desvios de recursos da Petrobras envolvendo servidores públicos, políticos e empresários. A esse respeito, ver matéria do jornal Zero Hora, disponível em: <http://zh.clicrbs.com.br/rs/ noticias/noticia/2014/11/entenda-a-operacao-lava-jato-as-empresasenvolvidas-e-o-impactono-rio-grande-do-sul-4646007.html>.

(6) Existem indicações de que os dois últimos cascos, da série de oito, serão cancelados pela Petrobras. O ERG, em crise financeira, tem seu caixa operado numa conta vinculada da Petrobras que autoriza pagamentos aos fornecedores (Sinaval, 2016, p. 2).

(7) Nota metodológica: os dados do Caged referem-se apenas aos empregos formais celetistas registrados, declarados pelos estabelecimentos ao Ministério do Trabalho (MTE), estando excluídos os empregos estatutários e os empregos e ocupações informais. É importante sublinhar, ainda, que esses dados estão sujeitos a ajustes, tendo em vista as declarações realizadas fora do prazo regular (Observatório Social do Trabalho - UFPEL, 2016). Disponível em: http://wp.ufpel.edu.br/observatoriosocial/2016/11/28/em-outubro-emprego-formal-cresceem-pelotas-mas-diminui-em-rio-grande/. Acesso em: 1ㅇdez 2016.

(8) O excerto apresentado na transcrição, conforme relato em entrevista realizada com o presidente do Sindicato dos trabalhadores (Stimmmerg).

(9) Ver mais em: http://www.valor.com.br/brasil/4289144/lava-jato-contribuiu-para-o-aumento-dodesemprego-diz-ipea. Acesso em: 21 jul 2016. 
(10) "O acordo de leniência, fruto da experiência norte-americana, é o ajuste que permite ao infrator participar da investigação, com o fim de prevenir ou reparar dano de interesse coletivo. [...] No Brasil, o Programa de Leniência da Secretaria de Desenvolvimento Econômico é uma das inovações na área do direito da livre concorrência, previsto no artigo 35-B da Lei 8.884/1994, acrescentado pela Lei 10.149/2000, e consiste na possibilidade de acordo entre a Secretaria (em nome da União) e a pessoa física ou jurídica envolvida na prática da infração a ordem econômica que confessar o ilícito, e apresente provas suficientes para a condenação dos envolvidos na suposta infração. Em contrapartida, o agente tem os seguintes benefícios: extinção da ação punitiva da administração pública ou redução de $1 / 3$ a 2/3 da penalidade" (De Camargo, 2004).

\section{Referências}

AMARAL, L. A.; GOMIDE, A. de A. e PIRES, R. R. C. (2014). "A revitalização da indústria naval no Brasil democrático". In: GOMIDE, A. A. e PIRES, R. R. C. (eds). Capacidades estatais e democracia: arranjos institucionais de políticas. Brasília, Ipea. Disponível em: http://www.ipea.gov.br/ portal/images/stories/PDFs/livros/capacidades_estatais_e_democracia_web.pdf. Acesso em: 20 jan 2015.

BOITO JR, A. (2012). As bases políticas do neodesenvolvimentismo. Trabalho apresentado na edição de 2012 do Fórum Econômico da FGV. São Paulo.

BONFIM, C. e JUSTI, A. (2016). PF cumpre mandados da 33a fase da Lava Jato e mira a Queiroz Galvão. G1,2/8/2016. Disponível em: http://g1.globo.com/pr/parana/noticia/2016/08/pf-cumpremandados-da-33-fase-da-operacao-lava-jato.html. Acesso em: 2 ago 2016.

BOSCHI, R. e GAITÁN, F. (2013). “Neodesenvolvimentismo". In: IVO, A. B. L. (coord). Dicionário temático desenvolvimento e questão social: 81 problemáticas contemporâneas. São Paulo, Annablume / Brasília, CNPq / Salvador, Fapesp (Coleção Trabalho e Contemporaneidade).

BRASIL (1997a). Lei no 9.432, de 8 de janeiro de 1997. Dispõe sobre a ordenação do transporte aquaviário e dá outras providências. Disponível em: http://www.planalto.gov.br/ccivil_03/leis/ 19432.htm. Acesso em: 15 jun 2016.

(1997b). Lei no 9.478, de 6 de agosto de 1997. Dispõe sobre a política energética nacional, as atividades relativas ao monopólio do petróleo, institui o Conselho Nacional de Política Energética e a Agência Nacional do Petróleo e dá outras providências. Disponível em: http://www.planalto. gov.br/ccivil_03/leis/L9478.htm. Acesso em: 15 jun 2016.

BRIDI, M. A. (2005). Sindicalismo e trabalho em transição e o redimensionamento da crise sindical. Dissertação de Mestrado. Curitiba, Universidade Federal do Paraná.

(2006). "As várias manifestações de crise no sindicalismo e a crítica ao pensamento generalizante de crise". In: ARAÚJO, S. M.; BRIDI, M. A. e FERRAZ, M. (orgs.). O sindicalismo equilibrista: entre o continuísmo e as novas práticas. Curitiba, UFPR.

BRESSER-PEREIRA, L. C. e THEUER, D. (2012). Um Estado novo-desenvolvimentista na América Latina? Economia e Sociedade. Campinas, v. 21, número especial, pp. 811-829. 
CARVALHAL, H. V. F. (2008). O afretamento de embarcações estrangeiras operadas por Empresa Brasileira de Navegação (EBN): afretamento marítimo. Brasília, 21 de agosto de 2008. Disponível em: http://www.antaq.gov.br/portal/pdf/palestras/Ago08OAfretamentodeEmbarcacoes.pdf. Acesso em: 29 nov 2016.

D'AVILA, A. P. F e BRIDI, M. A. (2015). As contratações na indústria naval em Rio Grande - Rio Grande do Sul. Política e Trabalho. Revista de Ciências Sociais, n. 43, pp. 319-339.

DE CAMARGO, M. F. (2004). O Acordo de Leniência no sistema jurídico brasileiro. Âmbito Jurídico. Rio Grande, VII, n. 17. Disponível em: <http://www.ambito-juridico.com.br/site/index.php?n_ link=revista_artigos_leitura\&artigo_id=3963>. Acesso em: 10 de ago 2016.

DORES, P. B. das; LAGE, E. S. e PROCESSI, L. D. (2012). A retomada da indústria naval brasileira. Banco Nacional do Desenvolvimento (BNDES). Ministério do Desenvolvimento, Indústria e Comércio Exterior.

FABRES, A. C. P. (2014). Indústria Naval de Rio Grande: modelo de trabalhadores da base produtiva. Monografia (Bacharelado em Ciências Sociais). Pelotas, Universidade Federal de Pelotas. Disponível em:<http://wp.ufpel.edu.br/observatoriosocial/files/2013/01/TCC-CIENCIASSOCIAISVERSAO-FINAL-13-MAR-2014.pdf>. Acesso em: 4 ago 2015.

FUNDAÇÃO PERSEU ABRAMO (2016). Pochmann: "A operação Lava Jato gera desemprego e leva à recessão". Disponível em: http://novo.fpabramo.org.br/content/pochmannopera\%C3\%A7\%C3\%A3o-lava-jato-gera-desemprego-e-leva-\%C3\%A0-recess\%C3\%A3o. Acesso em: 15 mar 2016.

G1 (2016a). Chegada de peças de plataformas gera expectativa de empregos no RS. Disponível em: http://g1.globo.com/rs/rio-grande-do-sul/noticia/2016/02/chegada-de-pecas-de-plataformasgera-expectiva-de-empregos-no-rs.html. Acesso em: 25 fev 2016.

(2016b). PF deflagra ação em estaleiro da Queiroz Galvão em Rio Grande, no RS. Disponível em: http://g1.globo.com/rs/rio-grande-do-sul/noticia/2016/08/pf-deflagra-acao-em-estaleiroda-queiroz-galvao-em-rio-grande-no-rs.html, 2 de ago. 2016. Acesso em: 2 ago 2016.

HABERMAS, J. (1980). A crise de legitimação no capitalismo tardio. Rio de Janeiro, Edições Tempo Brasileiro.

INSTITUTO BRASILEIRO DE GEOGRAFIA E ESTATÍSTICA (IBGE) (2015). Diretoria de Pesquisas, Coordenação de População e Indicadores Sociais. Rio Grande do Sul. Rio Grande. Disponível em: <http://www.cidades.ibge.gov.br/xtras/perfil.php?lang=\&codmun=431560\&search=rio-grandedo-sul|rio-grande>. Acesso em: 20 jul 2015.

KLEIN, J. (2016). Polo naval gaúcho tem encomendas por dois anos. Disponível em: http://jcrs.uol. com.br/_conteudo/2016/07/cadernos/empresas_e_negocios/511909-polo-naval-gaucho-temencomendas-por-dois-anos.html. Acesso em 1을 2016.

KREIN, J. D. (2016). A crise como pretexto para reeditar velhos ataques. IHU On-Line (Unisinos. Impresso), v. 484, Ano XVI, 2 de maio. Disponível em: http://www.ihuonline.unisinos.br/index. php?option=com_content\&view=article\&id=6423\&secao=484. Acesso em: 10 jun 2016.

LACERDA, A. C. (2016). A saída da crise ainda será demorada. Ponte para o passado. Jornal dos Economistas, n. 324, pp. 6-7.

MORIN, E. (1998). Sociologia: a sociologia do microssocial ao macroplanetário. Edição revista e aumentada. Portugal, Europa/América (Apartado 8). 
MUTIS, A. P. (2013). “Desigualdade e crescimento". In: IVO, A. B. L. (coord). Dicionário temático desenvolvimento e questão social: 81 problemáticas contemporâneas. São Paulo, Annablume / Brasília, CNPq / Salvador, Fapesp (Coleção Trabalho e Contemporaneidade).

NETO, C. A. da S. C. (2014). "Investimentos e financiamentos na indústria naval brasileira 2000-2013". In: CAMPOS NETO, C. A. da S. e POMPERMAYER, F. M. Ressurgimento da indústria naval no Brasil: (2000-2013). Brasília, Ipea.

PASIN, J. A. B. (2002). Indústria Naval do Brasil: panorama, desafios e perspectivas. Revista do BNDES. Rio de Janeiro, v. 9, n. 18, pp. 121-148. Disponível em: <http://www.bndes.gov.br/SiteBNDES/ export/sites/default/bndes_pt/Galerias/Arquivos/conhecimento/revista/rev1804.pdf>. Acesso em: 10 jul 2014.

PEREIRA, L. B. (2013). "Quando penso no futuro, não esqueço o meu passado: trabalho, direitos e memória na indústria naval do Rio de Janeiro". In: VERAS DE OLIVEIRA, R. e SANTANA, M. A. (orgs). Trabalho em territórios produtivos reconfigurados no Brasil. João Pessoa, Editora da UFPB.

POCHMANN, M. (2011). Políticas sociais e padrão de mudanças no Brasil durante o governo Lula. Revista SER Social. Brasília, v. 13, n. 28, pp. 12-40.

RAMALHO, J. R. e VÉRAS DE OLIVEIRA, R. (2013). A atualidade do debate sobre trabalho e desenvolvimento: introdução. CADERNO CRH. Salvador, v. 26, n. 68, pp. 211-215.

SINAVAL (2010). A indústria da construção naval e o desenvolvimento brasileiro - 2010. Disponível em: http://sinaval.org.br/wp-content/uploads/IndNaval-DesBrasil-2011.pdf. Acesso em: nov 2015.

(2012). Visão Geral da Construção Naval Brasileira. Disponível em: http://sinaval.org.br/wpcontent/uploads/SINAVAL-VisaoGeral-Mar2012.pdf. Acesso em: 13 dez 2015.

(2014). Cenário da Construção Naval - Balanço de 2014 e visão para 2015. Disponível em: http://sinaval.org.br/wp-content/uploads/Sinaval-Cen\%C3\%A1rio-2014-vis\%C3\%A3o-2015final-20-3-15.pdf Acesso em: 15 dez 2015.

(2015). Cenário da construção naval - Balanço de 2015. Disponível em: http://sinaval.org. br/wp-content/uploads/Cen\%C3\%A1rio-da-Constru\%C3\%A7\%C3\%A3o-naval-Balan\%C3\%A7ode-2015-17-12.pdf. Acesso em: 10 jan 2016.

(2016). Cenário da construção naval - 1o Semestre de 2016. Disponível em: http://sinaval. org.br/wp-content/uploads/Sinaval-Cen\%C3\%A1rio-da-Constru\%C3\%A7\%C3\%A3o-naval-1Semestre-2016-27-7-16.pdf. Acesso em: 28 out 2016.

SINCOMAM (2015). Desemprego: agrava-se crise no setornaval. Disponível em: http://www.sincomam. com.br/index.php/desemprego-agrava-se-crise-no-setor-naval/. Acesso em: 20 jul 2016.

TRASPDINI, R. S. e MANDARINO, T. M. (2013).Desenvolvimentismo X neodesenvolvimentismo na América Latina: continuidade e/ou ruptura? In: 37 ENCONTRO ANUAL DA ANPOCS. Disponível em: http://www.anpocs.org/portal/index.php?option=com_docman\&task=doc_ view\&gid=8393\&ltemid=459. Acesso em: 10 ago 2015.

VÉRAS DE OLIVEIRA, R. (2014). Brasil em obras, peões em luta, sindicatos surpreendidos. Revista Crítica de Ciências Sociais [Online], 103. Disponível em: http:// rccs.revues.org/5559. Acesso em: 20 jun 2015.

Texto recebido em 15/ago/2016

Texto aprovado em 26/nov/2016 